\title{
AUTOCONCIENCIA Y SER EN SANTO TOMÁS
}

\author{
Eudaldo Forment \\ Universidad de Barcelona
}

\begin{abstract}
RESUMEN
La memoria de sí le permite a Santo Tomás demostrar la existencia y la naturaleza del alma. También gracias a la conciencia de sí, el alma está presente a sí misma de un modo intelectivo, pero existencial, y puede relacionarse con los singulares, en su individualidad y en su existencia. Además, sin la conciencia del propio ser, no podría atribuirse el ser a las cosas, ni tampoco su posesión inmaterial, ni conocer algo de Dios
\end{abstract}

Palabras clàve: Santo Tomás, alma, conciencia de sí, Dios.

\begin{abstract}
The conscience allows Saint Thomas to prove the existence and the nature of soul. Thanks to the conscience, the soul is present in an intelective manner, but existencial and it can be connected to the singulars in thein individuality and in thein existence. Besides, without the own being's conscience, it would be impossible to attribute the being to the things or to their inmaterial presence or even to know something of God.
\end{abstract}

Key words: Saint Thomas, soul, conscience, God.

\section{METAFÍSICA TRINITARIA DEL ESPÍRITU}

Son muchas las doctrinas platónico agustinianas, que pertenecen de un modo muy central a la síntesis filosófica de Santos Tomás, y que forman parte de sus fundamentos. Sus contenidos, utilizados de un modo original, están perfectamente acoplados por la filosofía aristótelica. Podría decirse que el Aquinate, comprendendiendo en profundidad las tesis metafísicas de San Agustín, descubrió sus virtualidades, las conexió y asumió, utilizando para ello la filosofía de Aristóteles.

Una de estas doctrinas, que está incorporada como punto nuclear de la síntesis tomista, es la metafísica trinitaria del espíritu de San Agustín. Se advierte claramente en la siguiente objeción, que presenta Santo Tomás, al tratar la cuestión del hombre como imagen de Dios: «Dice San Agustín, en el libro La Ciudad de Dios (c. 26): el hombre fue hecho a imagen de Dios 'según lo que somos, y conocemos que somos, y amamos este ser y conocimiento'. Pero el ser no significa el acto del alma. Por lo tanto la imagen de Dios no se da en el alma según sus actos». ${ }^{1}$

1 Santo Tomás, Summa Theologiae, I, q. 93, a. 7, ob. 1. 
Responde, acudiendo también a San Agustín: «Nuestro ser pertenece a la imagen de Dios, lo cual nos eleva sobre los demás animales, y este ser nos compete por nuestra mente. Por elio, esta trinidad es idéntica a la que pone San Agustín, en La Trinidad (IX, c. 12), que consiste en la mente, la noticia y el amor». ${ }^{2}$

San Agustín, en este lugar citado, afirma: «Es, pues, cierta imagen de la Trinidad, la mente, su noticia, hijo y verbo de sí misma, y, en tercer lugar, el amor; y estas tres cosas son una sola substancia. Ni es menor la prole cuanto la mente se conoce tal como es, ni menor el amor si se ama cuanto se conoce y es». ${ }^{3}$

Para el autor del De Trinitate, la esencia del espíritu es tridimensional, por incluir: la mente, o su mismo ser, la noticia, o el conocimiento que tiene la mente de sí misma, y el amor, con que se ama a sí misma en su ser y en su conocimiento. La noticia que la mente tiene de sí misma, y el amor por el que la mente se ama a sí misma y a su noticia, constituyen una unidad o identidad substancial. En cuanto tales son relaciones, pero que se dan en una unidad substancial.

Además, si estas tres dimensiones son perfectas entonces son iguales. Si la noticia que la mente tiene de sí misma es perfecta, si alcanza a la mente totalmente, entonces es igual a ella. Si el amor es perfecto, es igual a la mente y a su noticia, tal como ocurre en Dios. En cambio, no ocurre así en la mente humana, por su noticia no alcanza la esencia de la mente, sólo su existencia; y se ama como algo inferior o como algo superior.

Concluye, por ello, Santo Tomás, que el hombre es imagen de Dios por su espíritu, que se manifiesta en sus dimensiones de mente, noticia y amor. La mente, tal como se afirma en la metafísica del espíritu de San Agustín, es el mismo ser espiritual, inmaterial, subsistente, inteligible a sí mismo e intelectual; la noticia o conocimiento es el conocimiento que tiene el alma de sí misma; y el amor es el que se tiene a sí misma. Por las tres, es imagen de la Trinidad.

En el cuerpo del artículo, al que pertenece esta objeción, afirma también que hay una imagen de la Trinidad más manifiesta en el espíritu humano gracias a sus tres facultades: memoria, entendimiento y voluntad. Ahora: «Se toma la imagen de la Trinidad en cuanto a los actos, es decir, en cuanto que por el conocimiento adquirido, pensando interiormente, formamos el verbo y de este pasamos al amor». ${ }^{4}$

Con San Agustín, el Aquinate sostiene que el alma humana, tiene noticia existencial de sí de una manera inmediata. Siempre tiene noticia de sí misma, ya que constantemente está presente a sí misma por sí misma. Cita el siguiente texto del De Trinitate: « la mente siempre se recuerda, siempre se conoce y ama a sí misma». ${ }^{5}$ Precisa en otra respuesta de este artículo, que ello no significa que: « en el alma se da el conocimiento y amor actual de sí». ${ }^{6}$ Nota que el mismo San Agustín añade en el último pasaje citado: «aunque no siempre crea que es diferente de todas aquellas cosas que no son lo que es ella». ${ }^{7}$

Según San Agustín no siempre esta el alma en presencia de sí misma con la misma plenitud. Explica que: «Su mirada es algo que pertenece a su misma naturaleza y, cuando piensa en sí misma,

2 Ibid., I, q. 93, a. 7, ad 1.

3 San Agustín, De Trinitate, IX, 12, 18.

4 Santo Tomas, Summa Theologiae, I, q. 93, a. 7, in c.

5 San Agustín, De Trinitate, XIV, 7, 9.

6 Santo Tomas, Summa Theologiae, I, q. 93, a. 7, ad 4.

7 San Agustín, De Trinitate, XIV, 7, 9. 
vuelve a su presencia, no mediante un movimiento espacial, sino por una conversión inmaterial. Más, cuando no se piensa, ciertamente no esta ante su vista ni informa su mirada; no obstante, se conoce como si ella fuera para sí su memoria». ${ }^{8}$

A esta presencialidad no pensada, pero conocida, de modo parecido a los conocimientos que tenemos en nuestra memoria, que no siempre pensamos en ellos, aunque los conocemos, le denomina, por ello, memoria. No tiene idéntico sentido a la facultad del recuerdo, pues esta memoria no ha requerido un aprendizaje. Ni tampoco es la mera capacidad para retener lo ya conocido, independientemente de como se haya obtenido, sino que es el alma misma constituida por la unidad de sus tres dimensiones: mente, noticia y amor.

Además, por ser memoria de sí, el alma guarda la permanencia de su ser, que es así algo presente siempre, en cambio, la memoria como recuerdo trae a la atención de la mente algo que también estaba oculto pero que es temporalmente pretérito. El alma, tiene, por tanto, una presencialidad entitativa, que por su misma memoria, puede hacerse consciente.

Explica Santo Tomás, al asumir esta doctrina, que la «memoria, según San Agustín, no es otra cosa que la retención habitual del conocimiento y del amon.$^{9}$ Más adelante, concluye: «Por lo dicho se ve que el alma siempre se conoce y se ama, no actual, sino habitualmente». ${ }^{10} \mathrm{La}$ distinción agustiniana entre autoconocimiento y autoconciencia de sí, queda de este modo precisada con la doctrina aristotélica del acto y la potencia, que no fue utilizada por San Agustín. La memoria se define como un conocimiento habitual y el pensamiento de sí, como actual.

Nota Santo Tomás que el conocimiento habitual de la propia existencia, o memoria existencial, no es idéntico al de los hábitos cognoscitivos el entendimiento. Los conceptos: «Están allí de un modo intermedio entre la potencia y el acto, o sea, en hábito, y entonces el hombre puede entender cuándo quieras. ${ }^{11}$ En cambio, el conocimiento existencial del propio ser no proporciona ningún concepto del propio yo, únicamente una percepción o experiencia individual y no esencial del alma. No obstante, tiene una cierta semejanza con ellos, en cuanto también en el cognoscente hay lo necesario para su actualización. $\mathrm{El}$ alma por su misma presencia, tiene una disposición para conocerse conscientemente en su existir.

El alma, como afirma San Agustín: «se conoce a sí misma por sí misma, pues es inmaterial». ${ }^{12}$ La memoria, o el conocimiento habitual fáctico y existencial de sí mismo, la unidad originaria de mente, noticia y amor, es la que permite el despliegue de la actividad inmanente del alma, la trinidad: memoria, inteligencia y voluntad. De la memoria nace la inteligencia, y de ella, por medio de la inteligencia, emana la voluntad.

\section{EL «COGITO» TOMISTA}

La memoria de sí le permite a Santo Tomás demostrar la existencia y la naturaleza del alma. Puede demostrarse de un primer modo por una investigación racional, que parte de la naturaleza de

8 Ibid., XIV, 6, 8.

9 Santo Tomás, Summa Theologiae, I, q. 93, a. 7, ad 3.

10 Ibid., I, q. 93, a. 7 , ad 4.

11 Idem, De anima, a. 15, ad 17.

12 San Agustín, De Trinitate, IX, 3, 3. 
los objetos entendidos para conocer la naturaleza de sus actos, a partir de estos la de las facultades, y desde ellas la substancia del alma. Explica sobre este modo de conocimiento indirecto, en la cuestión disputada De veritate: «Los filósofos han investigado la naturaleza del alma. Pues del hecho de que el alma humana conoce las naturalezas universales de las cosas, percibe que la especie por la que entendemos es inmaterial, ya que de lo contrario estaría individuada y así no conduciría al conocimiento de lo universal. Y del hecho de que la especie inteligible es inmaterial han deducido los filósofos que el entendimiento es cierta cosa independiente de la materia, y de aquí han procedido a conocer las otras propiedades de la potencia intelectiva». ${ }^{13}$ Este conocimiento proporciona un conocimiento analógico de su esencia.

En otro lugar, presenta una demostración parecida partiendo de la capacidad intelectiva del alma de conocer todos los cuerpos: «No cabe duda que el hombre puede por su entendimiento conocer la naturaleza de todos los cuerpos. más para que se puedan conocer cosas diversas es preciso que no tenga ninguna de ellas en la propia naturaleza, porque las que naturalmente estuvieran en ella impedirían el conocimiento de las demás (...) Luego es imposible que el principio de intelección sea un cuerpo». ${ }^{14}$

Un segundo argumento, que se encuentra en el pasaje citado del De veritate, proporciona un conocimiento directo, pero más limitado, del alma. Siguiendo a San Agustín sostiene Santo Tomás que: «Del alma pueden tenerse dos conocimientos, como dice San Agustín, De Trinitate, IX, 4), uno por el que se conoce sólo el alma de cada uno en cuanto a lo que le es propio; otro por el que el alma es conocida en cuanto a lo que es común a todas las almas. El conocimiento que se tiene del alma en cuanto de lo que es común a todas las almas es un conocimiento de la naturaleza del alma; el que tiene de su alma cada uno en cuanto a lo que le es propio, es el conocimiento que cada uno tiene de su alma, según que tiene ser en sí mismo como tal individuo. $Y$ así por este conocimiento se conoce si existe el alma, como cuanto alguien percibe que tiene alma; en cambio, por otro conocimiento se sabe qué es el alma y cuáles son sus propiedades». 15

En el texto citado de San Agustín se dice: «Todo hombre, atento a lo que en su interior experimenta expresa de una manera su mente al hablar y de otra muy diferente define lo que es la mente, sirviéndose de un conocimiento general o específico. Y así, cuando uno me habla de su propia mente y me dice que comprende o no comprende esto o aquello, o que quiere o no quiere esto o lo otro, le creo, más cuando de una manera general o específica dice la verdad acerca de la mente humana, reconozco y apruebo». ${ }^{16}$

La segunda manera de conocer la existencia del alma, y de algún modo su naturaleza, es inmediata, porque es por la percepción intelectual de la existencia de la propia alma. En el alma humana, con anterioridad a la recepción de las formas sensibles, a la abstracción de la imágenes sensibles, y al acto de intelección, hay una disposición permanente para conocerse a sí misma conscientemente, que es como un hábito intelectual, un conocimiento habitual existencial «Nuestro entendimiento no puede conocer nada en acto con anterioridad a la abstracción de las imágenes ni puede tampoco poseer un conocimiento habitual de las cosas distintas de sí misma, pero su esencia

13 Santo Tomás, De Veritate, q. 10, a. 8, in c.

14 Idem, Summa Theologiae, I, q. 75, a. 2, in c.

15 Idem, De Veritate, q. 10, a. 8, in c.

16 San Agustín, IX, 6, 9 
le es presente e innata, de modo que no necesita recibirla de las imágenes. Así la mente, antes de que abstraiga de las imágenes tiene conocimiento habitual de sí misma, por el que puede percibir que existe». ${ }^{17}$

Para Santo Tomás, el entender en el hombre no está rebajado hasta la pura potencia inteligible e intelectual, sino que está participado, según un modo humano, que es el del conocimiento habitual de sí mismo, que se actualiza al estar en acto de entender. Explícitamente afirma Santo Tomás de este conocimiento que: «Nadie puede pensar que él no existe, asintiendo a este juicio, pues en el acto mismo de pensar algo, percibe que existe». ${ }^{18}$

De manera que el alma humana no tiene siempre conciencia actual de su propio ser, sino solamente en cuanto está pensando. No se experimenta siempre en su existir, porque tampoco existe siempre en acto de entender. Por su misma esencia necesita que su entendimiento sea informado con la recepción de las formas a través de sus sensibilidad, y así ejercer la intelección de una manera actual. Por ello, se podrá experimentar por este acto, se podrá tener una autopresencia del alma.

Este conocimiento intelectual por el que cada uno percibe que existe al pensar algo, por no ser una intelección objetiva, tampoco es una intuición intelectual. Sin embargo, es una experiencia o percepción inmediata de la mente misma. Es un conocimiento que, en cuanto a su contenido, es inteligible y singular, y, en cuanto a su modo, perceptivo e inmediato. En el juicio en que se afirma la propia existencia, no se da una evidencia objetiva, de manera que de su negación no resulta algo incompatible con el principio de no contradicción, porque es contingente. Sin embargo, tiene una evidencia privilegiada, porque constituye a la conciencia en acto. Por ello, la percepción de la existencia del yo pensante acompaña a todo pensamiento en acto.

\section{FUNDAMENTALIDAD DE LA AUTOCONCIENCIA}

La inmaterialidad del alma humana la demuestra Santo Tomás por la primera modalidad de demostración. La segunda, basada en la autopresencia existencial no descubre la esencia inmaterial del alma, aunque si algo de su esencia, el saber que es una entidad substancial que es autoconciencia. Sin embargo, desde la primera, se llega también a la autoconciencia, y a la inmaterialidad que implica.

Esta primera demostración comienza presentando la tesis aristotélica sobre la no inteligibilidad en acto de las formas de los entes materiales, a causa de la materia que las individualiza. La ininteligibilidad de lo singular sensible se explica, por tanto, por su estructura hilemórfica. La materia, elemento potencial y recipiente de la forma, que es el constitutivo actual, da razón de su «accidentalidad», por ser principio de individuación. De manera que solo la forma permite que del singular se pueda predicar de su esencia.

Otra tesis aristotélica, correlativa con ésta, es que lo conocido directamente por el entendimiento humano es lo universal, obtenido por la abstracción de lo singular. Santo Tomás las presenta ambas en el siguiente pasaje: "Lo singular en las cosas materiales no puede nuestro entendi-

17 Santo Tomás, De Veritate, q. 10, a. 8, ad 1.

18 Idem, De veritate, q. 10, a. 12, ad 7. 
miento conocerlo directa y primeramente. La razón de ello es que el principio de la singularidad en las cosas materiales es la materia individual (...) por lo que nuestro entendimiento no es cognoscitivo directamente más que lo universal». ${ }^{19}$

La conocida doctrina hilemórfica no es el fundamento de estas dos tesis, que pueden sintetizarse con las afirmaciones: lo universal es entendido y lo singular es percibido. Por el contrario, la doctrina hilemórfica se puede justificar teniendo en cuenta que lo universal se predica de lo singular, y que éste último, aun siendo su sujeto, no queda totalmente dicho por los universales. La predicación no consigue definir la esencia concreta singular, y hay que postular que en esta esencia hay un constitutivo inteligible y predicable, que sería la forma, y otro que es una incógnita para el entendimiento, la materia.

En realidad, estas dos tesis aristotélicas, asumidas por Santo Tomás, se fundan en que los entes que verdaderamente son, que existen en la realidad, no son los universales inteligibles, como pretendía Platón con sus ideas, sino los concretos singulares. Para sostenerlo, Aristóteles tiene que reconocer su carácter no inteligible

Para el entendimiento humano, lo inteligible está en potencia en lo sensible. Para pasar al acto necesita ser abstraído por el entendimiento agente. Lo inteligible en potencia, que incluyen las imágenes de los entes materiales - ya que estos no son inteligibles en acto por su materia que les individualiza - hace que: «Sea preciso poner una virtud en el entendimiento, que haga inteligibles en acto, por abstracción de las condiciones materiales. Y, por esto, es necesario poner el entendimiento agente». ${ }^{20}$

Sostiene Santo Tomás que el entendimiento humano es a su vez intelectual en potencia, y necesita, para constituirse en intelectual en acto, de la «información» de lo inteligible. Compara este carácter potencial del entendimiento del hombre, en el género de las substancias intelectuales, con el de la materia prima, en el de las substancias sensibles, porque el entendimiento en cuanto potencia o sujeto carece de toda forma inteligible.

Afirma el Aquinate que la actualización del entendimiento posible, $o$ de la potencia intelectual del entendimiento, no es más que el convertirse en algo «uno» el intelectual y lo inteligible, el sujeto inteligente y el objeto entendido. Por ello: «Lo inteligible en acto es el entendimiento en acto» ${ }^{21}$.

Aristóteles había establecido que el cognoscente y lo conocido en acto son uno. En el entendimiento hay una cierta unidad. Puede decirse, por ello, que: «El inteligente y lo entendido en la medida que de ellos es efecto algo uno, que es el entendimiento en acto, son un único principio de este acto que es entender». ${ }^{22}$

En el acto de entender, por esta estricta unidad, no puede hablarse propiamente de sujeto y objeto, del inteligente y de lo entendido. Únicamente es posible mantener la distinción clásica de sujeto-objeto, en cuanto uno y otro existen en potencia. El entendimiento paciente o posible, en cuanto esta en potencia para ser intelectual, es el sujeto del conocimiento, y lo inteligible en potencia en la esencia sensible, para ser actualizado por el entendimiento agente, es el objeto. Para la comprensión del entendimiento en cuanto tal, no puede mantenerse el esquema dualista sujeto-obje- 
to, como se hizo en la modernidad. ${ }^{23}$ En el entendimiento paciente en acto desaparece la dualidad sujeto y objeto, aunque previamente en entendimiento humano, intelectual en potencia, y lo conocido, inteligible en potencia, guarden una relación de sujeto y objeto.

Esta unidad entre lo intelectual y lo inteligible permite comprender la afirmación de Cayetano de que conocer es ser. El gran comentarista de Santo Tomás escribió: «El entendimiento, procediendo de la potencia al acto, no procede sino a la perfección de su ser, y como el entender no es otra cosa que su ser, y la especie, la forma según la cual es aquel ser». ${ }^{24}$

Hay que tener en cuenta, para comprender adecuadamente la observación de Cayetano, que puede considerarse el entendimiento humano en cuanto existente en el alma humana, como una facultad o cualidad de la misma y también en cuanto cognoscente $o$ en su relación con lo conocido: Entitativamente el entender es una cualidad del sujeto. Cognoscitivamente es no sólo él mismo, sino también todo lo que conoce. ${ }^{25}$ El conocer es un ser intencional, y, por ello, acto. No hay por tanto una escisión entre lo inteligible y lo entitativo.

El conocer es ser y lo conocido es ente. De ahí la afirmación aristotélica según la cual: «el alma es de algún modo todas las cosas que son» ${ }^{26} \mathrm{El}$ alma de algún modo, es decir, en cuanto cognoscente, puede decirse que es el ser de todo lo conocido, el ser intencional inteligible, que se constituye como acto del sujeto haciéndole abierto a toda la realidad.

El conocimiento le es útil al hombre, explica Santo Tomás, para reparar su deficiencia en cuanto parte del todo, parte de toda la realidad creada, porque: «Una cosa puede ser perfecta de dos modos. De uno, en cuanto a la perfección de su ser, que le compete según su propia especie. Sin embargo, puesto que el ser específico de una cosa es distinto del ser específico de otra, por ello, a la perfección tenida de este modo, por cualquier cosa creada, tanto le falta de perfección absoluta cuanto más perfecta se encuentra en otras especies, de suerte que la perfección de una cosa, en sí misma considerada, es imperfecta, como parte que es de la perfección de todo el universo, la cual surge de las perfecciones de todas las cosas singulares unidas entre sí». Por ser parte del todo, el hombre posee esta clase de perfección, que, en realidad, es una perfección imperfecta.

Sin embargo, el hombre, tiene otra perfección que compensa esta limitación, porque: «Para que hubiese algún remedio a esta imperfección, se encuentra otro modo de perfección en las cosas creadas, según el cual la perfección, que es propia de una cosa, se encuentra en otra; y esta es la perfección del cognoscente en cuanto tal, porque, según esto, al ser conocido algo por el cognoscente, el mismo conocido de algún modo está en el cognoscente; y, por esto, dice Aristóteles, en III De Anima que 'el alma es en cierto modo todo', porque está hecha para conocerlo todo. Y según este modo, es posible que en una cosa exista toda la perfección del univerśo. De donde ésta es la última perfección a que podría llegar el alma, según los filósofos, que en ella se describiese todo el orden del universo y sus causas, en lo que pusieron el fin último del hombre». ${ }^{27}$

23 Cf. Francisco Canals Vidal, Sobre la esencia del conocimiento, Barcelona, PPU, 1987; y E. FORMENT, Lecciones de Metafisica, Madrid, Rialp, 1992.

24 Cayetano, In De Anima, II, c. 5. Cf. Francisco Canals Vidal, Sobre la esencia del conocimiento, op. cit., p. 290, n. 15 .

25 Cf. Francisco.Canals Vidal, Sobre la esencia del conocimiento, op. cit., p. 300, n. 24.

26 Aristóteles, De Anima, II, c 8, 43lb 2).

27 Santo Tomás, De veritate, q. 2, a. 2, in c. 
Toda esta compleja y profunda doctrina se puede sintetizar en dos tesis nucleares. La primera es la del carácter locutivo del entender. El concepto o verbo mental surge del entender en acto por este mismo acto. Esta locución intelectiva no es un acto distinto, sino que pertenece intrínsecamente al mismo acto intelectivo. El entendimiento es, por tanto, activo o creativo, porque, como afirma explícitamente el Aquinate: «Lo entendido, o la cosa entendida, se comporta como algo constituido $y$ formado por el entender». ${ }^{28}$

Esta actividad locutiva se fundamenta ontológicamente en el mismo entendimiento en acto. «La palabra mental no surge de nuestro entendimiento sino en cuanto éste existe en acto: pues simultáneamente es existente en acto y está ya en él el verbo concebido». La palabra mental no emana: «Según el brotar de la potencia al acto, sino que es al modo como surge el acto del acto, como el resplandor de la luz». ${ }^{29} \mathrm{El}$ entendimiento es, por tanto, doblemente activo. En cuanto tiene el entendimiento agente y en cuanto tiene el entendimiento paciente, en acto. La actividad es lo que lo constituye en cuanto tal. ${ }^{30}$

La segunda tesis, tan nuclear y fundamental como la anterior, es que este verbo mental es lo entendido. También formulada por Santo Tomás al indicar que: «Lo entendido en el inteligente es la intención entendida o el verbo». ${ }^{31}$ Esta tesis junto con la anterior se encuentran articuladas en este otro texto del Aquinate: «Siendo el verbo interior aquello que es entendido, y no existiendo en nosotros sino en cuanto entendemos en acto, el verbo interior requiere siempre el entendimiento en su acto, que es el entender». ${ }^{32}$

Estas dos tesis capitales sobre el entendimiento presuponen, en primer lugar, la afirmación de la apertura del entendimiento. El conocimiento intelectual no está encerrado en sí mismo, porque es manifestador de la realidad. El entendimiento en acto constituye un concepto, y en este decir interno, que es una palabra expresada, se entiende la realidad. La doctrina de Santo Tomás es realista porque implica la comprensión del entender como la constitución del concepto, o palabra mental, y que con este decir se expresa la realidad, lo que las cosas son. Declara el mismo Santo Tomás: «Tal concepción, o palabra mental (...) nace de algo y representa algo otro. Pues nace del entendimiento por su acto; pero es semejanza de la cosa entendida». ${ }^{33}$

El segundo presupuesto de las tesis centrales de la doctrina del conocimiento tomista - la locución intelectiva y la interioridad de lo entendido-, es que la presencia íntima del alma en su ser es anterior y originante de la intelección. La locución intelectual está inseparablemente unida a la autoconciencia. En el alma humana se da como un conocimiento habitual de sí misma, que proporciona la percepción intelectual de su existencia.

La autoconciencia, la conciencia de sí tiene un papel fundamental en la intelección. La autopresencia intelectiva, aunque sea mínima, como en el alma humana, es necesaria para explicar la intelectualidad propia del entendimiento humano, potencia intelectual, o capacidad receptiva respecto a los inteligibles, que han tenido que ser abstraídos de las imágenes. Si no se tiene conciencia de sí, no se puede asimilar de un modo consciente y objetivo ninguna esencia.

28 Idem, De Spiritualibus Creaturis., q. un., a. 9, ad 6.

29 Idem, Summa Contra Gentes, IV, c. 11.

30 Cf. Francisco Canals Vidal, La naturaleza de la actividad intelectual, en A. LOBATO, O. P. (Ed.), Giovanni di San Tommaso O. P. Il suo pensiero filosofico, teologico e mistico, Ati del convegno di Studio della SITA, Roma, Pontificia Università S. Tommaso d'Aquino, 1989, pp. 90-107.

31 Santo Tomás, Summa Contra Gentes, IV, c. 11.

32 Idem, De Veritate., q. 4, a. 1, ad 1. 


\section{LA AUTOCONCIENCIA Y EL ENTENDIMIENTO AGENTE}

También la autoconciencia posibilita la intelección en cuanto que es la raíz del entendimiento agente. «La mente misma es inteligible en acto, y según esto le compete el entendimiento agente que hace los inteligibles en acto». ${ }^{34} \mathrm{La}$ mente humana es inteligible en acto no por su intrínseca inteligibilidad, sino en cuanto es inteligible en hábito, y por esta actualidad el entendimiento puede ser activo con su entendimiento agente.

La doctrina del entendimiento agente de Santo Tomás, que asume de Aristóteles, puede asimismo considerarse como una interpretación dela doctrina de la iluminación de San Agustín, a pesar de que la escuela agustiniana del siglo XIII se ratificó en ella, como un motivo decisivo en su hostilidad a su recepción de Aristóteles. Santo Tomás considera que sigue y enriquece el iluminismo agustiniano, que ha sido siempre tan problemática y uno de los temas de más difícil interpretación de todo su pensamiento, con el aristotelismo.

Advierte que lo claro en el iluminismo es, en primer lugar, que si la mente juzga las cosas con juicio firme y absoluto lo hace en virtud de las razones eternas y divinas. En segundo lugar, que, para explicar que el hombre pueda juzgar a la luz de las razones divinas, hay que admitir una participación de su mente de la luz de las verdades eternas.

La explicación de San Agustín de la participación de la mente humana en la luz de la verdad eterna es interpretada, por Santo Tomás, como la presencia de una luz participada en la mente humana, que atribuye a la acción creadora de Dios. Admite, por tanto, no sólo la afirmación de Platón de que las ideas son "principios (...) de la producción de las cosas», expresada en el ejemplarismo agustiniano sino también la de que son «principios de conocimiento» ${ }^{35}$ para el hombre.

Para explicar el sentido de la tesis de San Agustín de que «el alma humana conoce todas las cosas en las razones eternas», ${ }^{36}$ en las ideas en cuanto «principios cognoscitivos», ${ }^{37}$ o en cuanto «conforme a ellas conoce las cosa el alma humana», establece Santo Tomás que: «Una cosa se conoce en otra de dos maneras. Una, como en objeto conocido, al modo como se ven en el espejo las cosas cuyas imágenes refleja. De esta manera el alma no puede en el presente estado de vida ver todas las cosas en las razones eternas; en cambio, así es como conocen los bienaventurados, los cuales ven a Dios y todas las cosas en Dios».

Según la doctrina del iluminismo de San Agustín, el entendimiento humano, en su estado actual, no adquiere su conocimiento de las esencias corporales viéndolas en la mente de Dios, como en un espejo, en un objeto conocido. Lo hace de una segunda manera, que señala a continuación. «Otra, como en su principio de conocimiento. Como si dijéramos que vemos en el sol lo que vemos por su luz. En este sentido es necesario decir que el alma humana conoce las cosas en las razones eternas, por cuya participación lo conocemos todo. Pues la misma luz intelectual que hay en nosotros no es más que una cierta semejanza participada de la luz increada en la que están contenidas todas las cosas» ${ }^{38}$

33 Idem, De Potentia., q. 8, a. 1, in c.

34 Idem, De veritate, q. 10, a. 6, in c. Véase: Francisco Canals Vidal, «El "lumen intellectus agentis" en la ontología del conocimiento de Santo Tomás», en Convivium (Barcelona), 1 (1956), pp. 99-116.

35 Santo Tomás, Summa Theologiae, I, q. 15, a. 3, in c

36 Ibid., 1, q. 84 , a. 5 , in c.

37 Ibid., I, q. 15, a. 3, in c.

38 Ibid., l, q. 84, a. 5 , in c. 
El Aquinate a esta luz participada por la que conocemos, la denomina «entendimiento agente», utilizando la terminología aristotélica. «Es menester que haya en el alma una potencia activa inmaterial que abstraiga las mismas imágenes de sus condiciones materiales, lo cual pertenece al intelecto agente; de suerte que éste es como una 'virtualidad' participada de una substancia superior, a saber, Dios», ${ }^{39}$

El alma humana, por su misma naturaleza intelectiva, que le hace intelectual e inteligile a sí misma, tiene el entendimiento agente. Posee un poder activo connatural, que le permite entender, y que es una participación del divino por el que Dios realmente posee las verdades eternas. De manera que: «El intelecto agente es cierta virtualidad de la que participan nuestras almas, algo así como cierta luz»; y añade: «la causa exterior de la cual participa está luz decimos que es Dios, quien nos instruye interiormente infundiendo a nuestra alma una luz de este tipo». ${ }^{40}$

En su intento de explicar, en este punto, el agustinismo con el aristotelismo, declara en este mismo lugar: «Por esto, afirma Aristóteles (De anima, III, 5) que el intelecto agente es como un hábito y una luz, y en los Salmos (IV, 7) se dice: 'Señor, sobre nosotros, está sellada 'la luz de vuestro rostro'. Y algo semejante sucede en los animales, que ven de noche; sus pupilas están en potencia para todos los colores, sin tener en acto ningún color determinado. Pero en virtud de una especie de luz inmanente a ellos, de alguna manera hacen los colores visibles en acto». ${ }^{41}$ Sobre este versículo del Salmo, comenta también: «Como si dijera: Por el sello de la luz divina en nosotros todo se da a conocer». ${ }^{42}$

Precisa que , no obstante: «El intelecto agente no es tal que su acto tenga por objeto las especies de las cosas, como tampoco la luz puede hacer que la facultad visiva conozca cualquier especie de color, sino sólo la de aquellos colores que están presentes a la facultad visiva». ${ }^{43}$ Afirma que el entendimiento agente «por su substancia está en acto», ${ }^{44}$ pero su actuación espontánea no consiste en producir los objetos inteligibles, sino su actualidad. «El intelecto agente hace que los mismos inteligibles que antes eran en potencia sean en acto, por esto los abstrae de la materia».

La acción del entendimiento agente no es la de determinar el contenido de los inteligibles, que se encuentra en las imágenes sensibles, aunque en potencia, por la materia que constituye a los cuerpos y que además los individualiza. El intelecto agente: «En consecüencia, respecto a los inteligibles se compara como acto en cuanto es cierta capacidad activa inmaterial, que puede hacer todas las cosas semejantes a sí mismo. es decir inmateriales. De este modo, aquellas cosas que son inteligibles en potencia, las hace inteligibles en acto, como la luz hace los colores en acto no porque en sí misma posea la determinación de todos los colores» ${ }^{45}$ Por consiguiente: «Porque además de la luz intelectual para conocer las cosas materiales necesitamos las especies inteligibles que provienen de los mismos objetos, hay que concluir que no conocemos las cosas materiales sólo por la participación de las razones eternas, como decían los platónicos afirmando que la sola participación de las ideas es suficiente para tener ciencia». ${ }^{46}$

IDEM, De anima, q. un, a. 5, in c.

Ibid., q. un, a. 5 , ad 6.

Ibid., q. un, a. 5 , in c.

42 IDEM, Summa Theologine, I, q. 84, a. 5, in c,

43 IDEM, De anima, q. un, a. 5, ad 6.

44 IDEM, In III De anima, lect. X, n. 732.

45 Ibid., n. 739.

46 Ibid., n. 131. 
Sin embargo, Santo Tomás no considera que en esto último San Agustín siguiera a Platón, y cita para corroborarlo el siguiente texto: «¿Acaso porque los filósofos demuestran con pruebas irrefutables que todo lo temporal fue hecho en virtud de las razones eternas, han podido ver en ellas o deducir de ellas cuántas son las especies de animales y cuántos los principios germinales de cada uno? ¿Acaso no acudieron, más bien, al análisis de la historia de tiempos y lugares?» ${ }^{47}$

En definitiva, San Agustín: «No entendió que todas las cosas son conocidas 'en las razones eternas' o 'en la verdad inmutable' en el sentido de que viésemos las mismas razones eternas». Santo Tomás citándole escribe a continuación: «Está claro por lo que dice en Ochenta y tres cuestiones diversas $(46,2$,): 'No toda ni cualquier alma racional es considerada apta para esta visión», es decir, las de las razones eternas, 'sino la que fuere santa y pura', como son las almas de los bienaventurados». 48

Con esta nueva y original exégesis de la doctrina de la iluminación divina, Santo Tomás no sólo cree que ese salvan todas sus tesis, sino que también se evitan todas la imprecisiones y confusiones de las interpretaciones tradicionales. No considera, por tanto, que derogue el iluminismo agustiniano. No sólo en cuanto que Dios ilumina a todos los hombres con su luz espiritual, sino también en relación a sus mismas ideas o verdades inteligibles iluminadas por Dios, que actúan sobre la mente humana.

El entendimiento del hombre tiene, por tanto, algún contacto con estas verdades inmutables y necesarias de la mente divina. Este segundo aspecto es igualmente afirmado explícitamente por San Agustín, al escribir: «Es más creíble que hasta los ignorantes respondan cosas verdaderas sobre algunas disciplinas, cuando son bien interrogados, precisamente porque, en cuanto pueden comprenderlo, tienen presente la luz de la razón eterna, en la cual ven estas verdades inmutables, no porque alguna vez las hayan conocido y se hayan olvidado, como creyeron Platón y otros». ${ }^{49}$

El Aquinate explica también cómo se ven estas verdades inmutables. Para ello comienza indicando que: «Platón (...) para establecer la certeza de la ciencia, puso, por una parte, las especies de las cosas separadas de lo sensible e inmutables, sobre las que estableció que era la ciencia. Por otra, puso en el hombre una virtud cognoscitiva superior al sentido, a saber, la mente o entendimiento, que dijo que era iluminada por cierto superior sol inteligible, así como la vista es iluminada por el sol visible». ${ }^{50}$

Por consiguiente, la iluminación implica un cierto conocimiento de las Ideas. Sin embargo, advierte que: «Platon dijo que las ciencias eran sobre las especies separadas, no porque éstas mismas fuesen vistas; sino según que nuestra mente, participando de ellas, tiene ciencia de las cosas Por lo que en cierta glosa, sobre aquello del Salmo 11: 'Han sido disminuidas las verdades por los hijos de los hombres, se dice que, al modo como en muchos espejos se reflejan muchas imágenes de un mismo rostro, así resultan muchas verdades en nuestras mentes procedentes de una sola verdad primera». ${ }^{51}$

47 San Agustín, De Trinitate, IV, c. 16, ML 42, 902. Cf. IDEM, Summa Theologiae, I, q. 84, a. 5, in c.

48 Santo Tomás, Summa Theologiae, I, q. 84, a. 5, in c.

49 San Agustín. Las Retractaciones, I, 4, 4.

50 Santo Tomás, De spiritualibus creaturis, q. un., a. 10 , ad 8.

5l Ibid. San Agustín al comentar este versículo dice: «Una sola es la verdad, por la que son iluminadas las almas santas; pero como hay muchas almas, puede decirse que hay muchas verdades en ellas, así como de una cara aparecen muchas imágenes en los espejos» (San Agustín, Comentarios a los Salmos, I, 11, 1). 
Sin embargo, San Agustín, aunque seguía a Platón, : «No afirmó que las especies de las cosas eran por sí subsistentes, sino que en su lugar puso las razones de las cosas en la mente divina, y sostuvo que por ellas juzgamos sobre las cosas según el entendimiento iluminado por la luz divina».

Mantuvo, por tanto, los dos elementos de la doctrina del conocimiento platónico: la iluminación y la intervención de las ideas. «Pero no de manera que veamos las mismas razones divinas, pues esto sería imposible, a no ser que viésemos la esencia de Dios; sino según que aquellas razones supremas imprimen en nuestras mentes». ${ }^{52}$ Las Ideas actúan en nuestra mente imprimiendo sus imágenes en ella, como un objeto en un espejo, o un sello en la cera.

Reconoce Santo Tomás que: «Aristóteles procedió por otro camino (...) afirma que por encima de los sentidos está la virtud intelectiva, que juzga sobre la verdad, no por algunos inteligibles que existan fuera del alma, sino por la luz del entendimiento agente, que hace los inteligibles. Y no importa mucho el que se diga que de Dios participan los mismos inteligibles, o bien que de él se recibe la luz que hace los inteligibles».53

Todos los elementos de la iluminación divina se pueden explicar por las actividades naturales puestas por Dios. Interpretación que está inspirada en un pensamiento característico de Santo Tomás, que no disminuye el teocentrismo: hay que reconocer la actividad de las criaturas en virtud de los principios activos puestos en ellas por Dios. De este modo incluso queda mejor afirmada la omnipotencia divina.

Dejando aparte esta interpretación, puede decirse que lo más fundamental en la doctrina conocimiento de Santo Tomás, y también de la de San Agustín, no es la intencionalidad, aunque sea perfectiva del sujeto por remediar su finitud entitativa, sino la autopresencia en el acto de entender. De manera que la actual intelectualidad y la actual inteligibilidad propia se identifican formalmente.

Para Santo Tomás, la intelectualidad, y la inteligibilidad que le acompaña y fundamenta, posibles ambas por su inmaterialidad, se identifican. Entender, autoconciencia e inmaterialidad coinciden. El alma humana, por su estructura sensitivo racional no se le puede atribuir una más perfecta intelectualidad que una posible por la capacidad receptiva de la mente respecto de los inteligibles, que ha abstraído de las imágenes sensibles, y una cierta inteligibilidad, consistente en un conocimiento habitual de sí mismo, por el que tiene experiencia existencial de sí mismo, al ponerse en acto por el pensar. Posee, por tanto, una intelectualidad potencial, que al actualizarse manifiesta la realidad en su esencialidad, una inteligibilidad habitual, que le proporciona una percepción intelectiva de su ser y que le permite y gracias a esta última, un entendimiento agente activo iluminado e iluminativo.

\section{AUTOCONCIENCIA Y CONVERSIÓN A LA IMAGEN}

Por la autoconciencia, el alma se relaciona consigo mismo, está presente a sí misma de un modo intelectivo pero existencial. También gracias a la conciencia de sí el alma puede relacionarse con los singulares, en su individualidad y su existencia. A este conocimiento indirecto del singular, Santo Tomás lo caracteriza como una «conversión a la imagen».

52. SANTO TOMÁS, De spiritualibus creaturis, q. un., a. 10 , ad 8.

53 Cf. IDEM, Stumma Theologiae, I, q. 84, a. 5, in c. 
Esta conversión a la imagen es como una reflexión, que se realiza por la vía perceptiva de los principios concretos, que dan lugar a la intelección. De manera que: «La mente conoce el singular por cierta reflexión en cuanto, al conocer su objeto, que es la naturaleza universal, vuelve sobre su acto y ulteriormente a la especie, que es su principio del acto, y ulteriormente a la imagen de la que la especie ha sido abstraída; y así tiene algún conocimiento del singular». ${ }^{54}$

Debe entenderse que las reflexiones sobre el acto, sobre la especie impresa y sobre la imagen no se realizan de una manera discursiva, como si los tres contenidos fuesen objetos inteligibles, que se obtuvieran sucesivamente a partir de lo entendido, la esencia de las cosas. No se trata de reflexiones sobre conceptos, sino sobre aspectos que se revelan en la profundización de la conciencia. Son conocimientos perceptivos e intelectivos de la conciencia.

Como se ha dicho, el entendimiento al pensar algo se percibe intelectualmente como existente, pero además también como viviente y pensante. Se experimenta intelectivamente en sus mismas operaciones intelectuales. Santo Tomás describe así esta experiencia del alma: «Respecto al conocimiento actual, por el que alguien considera que él tiene actualmente alma, digo que el alma se conoce por sus actos. Porque en esto percibe alguien que tiene alma y que vive y que existe, en que percibe que él siente y entiende y ejerce otras operaciones vitales semejantes. Y, por esto, dice Aristóteles (Ética a Nicómaco, IX, 9): 'En el hecho de que nosotros sentimos que sentimos y entendemos que entendemos, sentimos y entendemos que nosotros existimos'. Pero nadie percibe que entiende sino porque entiende algo, porque es primero entender algo, que percibirse como inteligente, y así el alma alcanza a percibir actualmente que existe, por cuanto entiende y siente». ${ }^{55}$

No son actos idénticos el de entender y el de la autoconciencia que le acompaña, pero ambos pertenecen a la simplicidad del acto de entender. Pueden considerarse como dos actos implicados o comprendidos mutuamente, o como dos fases de un mismo acto, que es el entender, que no suponen una estructura acto-potencial o una inherencia accidental-substancial. En un mismo acto el alma entiende lo inteligible, expresándolo en la locución mental, y se entiende, en cuanto se percibe intelectivamente, a sí misma.

El alma, mientras entiende la realidad, en la fase locutiva del entender, nota su presencia íntima, pero además la especie inteligible impresa, porque, aunque sea un principio del acto de conocer está también presente en la conciencia. Afirma Santo Tomás que: «Es connatural al entendimiento humano el ver las especies inteligibles en las imágenes (...) Sin embargo, el conocimiento intelectual no consiste en aquellas imágenes, sino contemplar en ellas la pura verdad». ${ }^{56}$

Explica el Aquinate que. «Nuestro entendimiento abstrae la especie inteligible de la imagen, en cuanto considera la naturaleza de las cosas en general; porque no puede entender a la imagen de la que se abstrae la especie, a no ser por la conversión a la imagen». ${ }^{57}$

Por la misma reflexión, que es una percepción intelectiva de los principios de la intelección, se entiende el acto de entender, la especie por la que se entiende, y la imagen de la que procede. En esta «cierta reflexión» se va profundizando desde el acto de entender, que puede considerarse un elemento objetivo, en cuanto que «el acto es más próximo al objeto que la especie», ${ }^{58}$ hasta los principios subjetivos como la especie y la imagen .

55 Ibid., q. 10, a. 8, in c.

56 IDEM, Summa Theologiae, II-II, q. 180, a. 5, ad 2.

57 Ibid, I, q. 85, a. 2 , ad 5.

58 IDEM, De Veritate, q. 10, a. 9, ad 5. 


\section{SER, VIDA Y AUTOCONCIENCIA}

La esencia de la autoconciencia revela la absoluta inmaterialidad de la facultad de entender y su sujeto el alma, tanto de la propia como la de los demás almas humanas. Sin la conciencia del propio ser, no podría atribuirse el ser a las cosas, ni tampoco su posesión inmaterial por las almas humanas. No sería tampoco posible conocer algo del ser divino no participado, el mismo Ser Subsistente.

La inmaterialidad, el entender o la intelectualidad y la inteligibilidad o autoconciencia, que se exigen mutuamente se explican por el subsistir en sí mismo, el poseer un ser propio no compartido con la materia. Por la misma posesión de su ser, las formas subsistentes están presentes a sí mismas. Poseen de modo consciente el propio ser. De manera que: «Volver a su esencia no significa otra cosa que el subsistir una cosa en sí misma. Pues la forma, en cuanto tiene ser en sí misma, se dice que vuelve sobre sí misma». ${ }^{59}$

La substancia inmaterial, la forma que subsiste, que posee un ser propio, y que, por ello, es inteligible para sí misma e intelectual. Formalmente autoconciencia y entender no sólo coinciden entre ellos, y con la inmaterialidad sino que también se identifican con la propia subsistencia. Afirma, por ello, Santo Tomás que: «Si una arca pudiese subsistir en sí misma, se entendería a sí misma, puesto que la inmunidad de la materia es la razón esencial de la intelectualidad». ${ }^{60}$

Lo que constituye al espíritu es la posesión del ser por su forma con independencia de la materia, que hace consciente de sí mismo y que permite el conocmiento de la realidad es lo que constituye al espíritu a la la substancia inmaterial o a la forma subsistente. Al espíritu, que en cuanto tal comporta la remoción de lo material y potencial, Santo Tomás lo relaciona con el ser y el grado viviente.

En la escala de los entes, la ordenación es por los grados de perfección. La gradación en las perfecciones, colocadas en orden creciente, se hace por el grado de participación en el ser. Las perfecciones no se conciben como concreciones o determinaciones categoriales, como determinaciones de la sustancia, sino como grados en la más y más perfecta participación del ser. No se conciben unívocamente, de manera que al perfección ascendente sea por la adición de diferencias genéricas o específicas. La menor o mayor particpación en ser o en şus grados, expresada de una modo analógico.

En la Suma teológica, Santo Tomás lo hace contestando a la siguiente objeción a la afirmación de que en Dios están las perfecciones de todos los entes: «El viviente es más perfecto que el ente, y el inteligente lo es más que el viviente. Luego, vivir es más perfecto que ser, y saber es más perfecto que vivir. Pero la esencia de Dios es su mismo ser. Luego, no tiene en sí la perfección de la vida y la sabiduría y otras perfecciones parecidas». ${ }^{61}$

Reconoce el Aquinate que el viviente es más perfecto que el que sólo es ente, y carece de vida; y el que tiene una naturaleza cognoscente intelectual, el que es espíritu, es más perfecto que el viviente carente de inteligencia. A pesar de ello, se puede sostener que en Dios, aunque sea el mismo ser, se hallan las perfecciones de todo, que es universalmente perfecto.

59 IDEM, Summa Theologiae., I, q. 14, a. 2, ad 1.

60 IDEM, De Spiritualibus creaturis, q. un., a. 1 , ad 12.

61 IDEM, Summa Theologiae, I, q. 4, a. 2, ob. 3. 
En la correspondiente respuesta explica que: «Dionisio dice en el capítulo V de Los nombres divinos que el ser es más perfecto que la vida, y la misma vida más perfecta que la misma sabiduría, aunque el viviente es más perfecto que el ente sólo, porque además de viviente es también ente; y el inteligente es ente y viviente, si se consideran según que se distinguen por la razón. Así, pues, aunque el ente no incluya en sí al viviente y al inteligente, porque no es preciso que todo aquello que participa del ser, participe el mismo del ser en todos sus grados; sin embargo, el ser de Dios incluye en sí la vida y la sabiduría, porque ninguna de las perfecciones del ser puede faltarle a quien es el mismo ser subsistente». ${ }^{62}$

$\mathrm{Si}$ se tiene en cuenta que la perfección suprema de ser, que es el que hace que algo sea ente, viviente e inteligente, es preciso sostener que la mayor universalidad del concepto de vida respecto al de inteligente, y del concepto de ente repecto a ambos, ello no supone una mayor potencialidad a modo de género, sino una mayor perfección y en todos sus grados. Si consideramos el ser, la vida y la sabiduría en su concepto esencial nos aparecen en una perspectiva aparentemente inversa con que se nos muestran las perfecciones de ser, vivir y entender en la escala de los entes, porque hay que reconocer que el ser es más perfecto que la vida, y la misma vida más perfecta que la sabiduría.

En la escala de los ente se resuelve la aparente antinomia antinomia por la que la vida y el espíritu se presentaban situados por encima del ente, ya que tanto la vida como el espíritu están constituidas por la propia perfección y actualidad del ser mismo. Si el ser no fuese más profundo que el vivir, quedaría, entonces, sin explicar la vida. Igualmente si el vivir no fuese más profundo que el entender, quedaría el espíritu desvirtualizado. No se da ninguna escisión entre la vida y el espíritu, como en otros sistemas filosóficos, ni tampoco, como en otros, los enfrentamientos entre «naturaleza», vida y espíritu. En la graduación de la escala de los entes el espíritu creado participa del ser y de la vida, que a su vez es una participación del ser; y el espíritu del primer ente incausado es el ser y la vida.

\section{EMANACIÓN E INTERIORIDAD}

En el capítulo 11 del libro IV de la Summa contra gentiles, Santo Tomás ordena los entes en perfección por el grado de intimidad de los efectos que producen sus operaciones, y, por tanto, por la autoconciencia. Para detectar la perfección de la operación, indica que: «Debemos tomar como punto de partida que en las cosas hay diversos modos de emanación correspondientes a la diversidad de naturalezas, y que, cuanto más alta es una naturaleza tanto más íntimo es lo que de ella emana». ${ }^{63}$

También hay que tener en cuenta que, como se explica en la Suma Teológica: «El primer ser de las cosas es el ser substancial por el que decimos que las cosas son entes en sentido absoluto y buenas de algún modo. En cambio, cuando se las considera en posesión de su último acto, decimos que son buenas en sentido absoluto y entes de alguna maneras. ${ }^{64}$

62 Ibid., I, q. 4, a. 2, ad 3.

63 IDEM, Summa contra gentiles, IV, c. I1.

64 IDEM, Summa Theologiae, I, q. 5, a. I, ad I. 
Las últimas perfecciones del ente, que son siempre accidentales, no las confiere el ser substancial, el que hace que el ente esté en acto. Al ente substancial no puede denominarse, por ello, ente bueno de modo absoluto, sino de alguna manera, la de la substancia. En cambio, el ente finito puede denominarse bueno absolutamente en cuanto perfeccionado por los accidentes, actos últimos. que advienen a la substancia ya constituida en sus perfecciones fundamentales. A estas perfección últimas, $o$ accidentales, que se adquieren al obrar, se tiende por la propia naturaleza substancial. «De la forma se deriva la inclinación al fin, a la acción y a otras cosas, porque los entes que están en acto obran y tienden a lo que les es provechoso con arreglo a su forma». ${ }^{65}$

Precisamente los agentes imperfectos obran en razón de su imperfección entitativa. Para poder remediarla, buscan estas perfecciones accidentales. Afirma, por ello, el Aquinate, que: «Hay algunos agentes que simultáneamente obran y reciben los cuales son agentes imperfectos. A estos les compete el que aún al obrar ellos intenten adquirir algo». ${ }^{66}$

El fin de la operación en sí mima no es la de perfeccionar a su sujeto. La operación en cuanto tal está ordenada a difundir la propia perfección. La imperfección de la criatura es la que hace que esté dirigida a su perfección propia, a la del sujeto que obra. Por ello: «La inclinación de la naturaleza es doble: a saber, a ser movida y a obrar. La inclinación de la naturaleza al movimiento es inclinación recurva en sí misma (...) pero no así la inclinación a obrar, que busca la perfección y el bien de lo generado, y también el bien común del universo». ${ }^{67}$

En la operación se pueden distinguir dos fines. La inclinación al movimiento y a la acción, propias de los entes en potencia en cuanto están en potencia, y la inclinación del ente en acto, que lo es a difundir su propia perfección. La acción, en este último caso, no puede situarse en una categoría de lo finito e imperfecto. En cambio, la acción de las criaturas, que poseen entidad potencial, pertenece al orden categorial o predicamental. Acción, que puede considerarse como una limitación de la operación en cuanto tal.

La estructuración acto potencial de la criatura hace que su operación no sea absolutamente una efusión donante, propia del acto en sí mismo, porque: «Es de la naturaleza de cualquier acto el que se comunique a sí mismo según le es posible. Con lo cual todo agente obra según que es en acto. Y obrar no es otra cosa sino comunicar aquello por lo que el agente es en acto». ${ }^{68}$

Desde esta concepción del obrar, establece Santo Tomás, en el pasaje de la gradación de los entes, que: «En todas las cosas, los cuerpos inanimados ocupan el último lugar, y en ellos no se dan otras emanaciones que las producidas por la acción de unos sobre otros. Así vemos que del fuego nace el fuego cuando éste altera un cuerpo extraño convirtiéndolo en su especie y cualidad». Los entes sin vida ocupan el lugar inferior en la escala de los entes, porque carecen de una unidad interior activa, que se despliegue en una acción inmanente. Sólo emana algo de ellos, por la acción transitiva de otro ente. De ahí que en el modo de su actividad manifiestan una extroversión completa.

Se encuentra ya introversión, en los entes que les siguen y que ya poseen la vida.. «Entre los cuerpos animados, el lugar próximo lo ocupan las plantas, en las cuales la emanación ya procede de 
dentro, puesto que el 'humor' interno de la planta se convierte en semilla, y ésta confiada a la tierra, se desarrolla en planta. Esto es ya un primer grado de vida, pues son vivientes los entes que se mueven a sí mismos para obrar, en cambio, los que no tienen movimiento interno carecen en absoluto de vida. $\mathrm{Y}$ un indicio de vida en las plantas es que lo que hay en ellas tiende hacia una forma determinada».

En el primer grado de vida, se da ya un primer indicio de interioridad. En la vida vegetativa, se generan las semillas, emanaciones que surgen de la propia savia de las palntas , y que asegurarán la permanencia de su especie. Tal modo de emanación no es, sin embargo, perfecto. «La vida de las plantas es imperfecta, porque, aunque la emanación proceda en ellas del interior, sin embargo, lo que emana saliendo poco a poco desde dentro, acaba por convertirse en algo totalmente extrínseco. Pues el humor del árbol, saliendo primeramente de él, se convierte en flor y después en fruto, separado de la corteza del árbol, pero sujeto a él; y llegando a su madurez, se separa totalmente del árbol y, cayendo en tierra, produce por su virtud seminal otra planta».

A diferencia de los entes inertes, en las plantas, y también en los animales, pero no en cuanto a su animalidad, se da la generación vegetativa, una emanación propia. No obstante, es imperfecta todavía. Por una parte, porque el fruto de la generación se exterioriza. Por otra, porque: «El principio de esta emanación proviene del exterior, puesto que el humor interno del árbol se toma mediante las raíces de la tierra, de la cual recibe la planta su nutrición». En su inicio y en su fin, hay exteriorización.

La perfección emanativa no termina en la vida vegetativa. «Hay otro grado de vida superior al de las plantas y correspondiente al alma sensitiva, cuya propia emanación, aunque comience en el exterior, termina interiormente y, a medida que avanza la emanación, penetra en lo más íntimo. Por ejemplo, lo sensible imprime exteriormente su forma en los sentidos externos, pasa de ellos a la imaginación y después al tesoro de la memoria».

Se ha ascendido en perfección, porque la generación sensitiva muestra una menor exteriorización y, con ello, un progreso en la posesión de los principios internos, que posibilitan la emanación. Por esta menor dependencia de lo exterior, este grado inmediato de vida posee una mayor autonomía. Con la emanación propia de esta concepción animal, el conocimiento sensible, se poseen otras formas, distintas de la forma substancial propia, que condicionarán la acción. El ámbito vital se ampliará. No quedará limitado en un espacio como las plantas, ni a estar constreñido o arrinconado en el espacio como los entes inertes

Se da una mayor interioridad, y, por tanto, mayor perfección, con el conocimiento sensible. Aunque su fruto, las imágenes sensibles se han constituido exteriormente, por originarse por un estímulo exterior, ya no se perfeccionan en el exterior del animal, sino que se continúan en la imaginación, pasando, por último, a almacenarse en la memoria sensible. Se empieza así a vencer el espacio y el tiempo.

En la vida sensible, la interiorización, tampoco es completa. «En cada proceso de esta emanación, el principio y el término obedecen a cosas diversas, pues ninguna potencia sensitiva vuelve sobre sí misma, luego, este grado de vida es tanto más alto que el de las plantas cuando más íntima es la operación vital; sin embargo, no es una vida enteramente perfecta, porque la emanación pasa siempre de uno a otro». En este grado de la escala ascendente de los entes, nay más inmanencia o interioridad que en el anterior, pero por ser distintos su principio y su fin, no es perfecta. En la interioridad sensitiva no es posible, por ello, la reflexión de sus potencias sensitivas, de actuarse a sí mismas. 
La perfecta inmanencia se da, en el siguiente grado de interioridad, en la generación intelectual. «Hay un grado supremo y perfecto de vida, que corresponde al entendimiento, porque éste vuelve sobre sí mismo y puede entenderse».

En la vida intelectual o espiritual, se manifiesta el modo más alto de intimidad, porque confiere el poder de reflexionar. El viviente intelectual, con la reflexión, adquiere el poder de ser dueño de su propio juicio, y, por tanto, de sus designios. En este grado de vida, tanto la actividad y su perfección son interiores. Con la perfección intelectual, la operación ya no es extrovertida ni en su principio ni en su fin.

La perfección del obrar está en la vida intelectual, porque se desarrolla en el interior, en la intimidad. Sin embargo, advierte Santo Tomás que: «En la vida intelectual hay también diversos grados. Pues, aunque el entendimiento humano pueda conocerse a sí mismo, toma sin embargo, del exterior, el punto de partida para su propio conocimiento, ya que es imposible entender sin contar con una representación sensible».

Como afirma Santo Tomás en el De veritate, en el alma humana hay una disposición para conocerse conscientemente, para poseer intelectualmente su ser, a modo de un hábito intelectual. Este conocimiento habitual no se refiere al concepto del alma, no pertenece a la línea de la esencia, sino a su existencia y singularidad. Disposición que se actualiza en el acto de pensar. En todo pensamiento en acto está implicada la percepción intelectual inmediata de la existencia del yo pensante, de la mente misma, la conciencia intelectual no objetiva de su propio ser

Siendo el alma una substancia inmaterial, por subsistir en sí misma y, por tanto, por tener un ser propio, no compartido zon la materia, posee su ser de modo consciente, está presente a sí misma. Sin embargo, por su emplazamiento inferior en el grado de las substancias inmateriales, por su menor participación en el ser, al igual que su intelectualidad, su inteligibilidad propia es imperfecta. No se manifiesta de un modo puramente espiritual. Su entendimiento es potencial con respecto a los inteligibles y su inteligibilidad está hábito, pero por esta cierta actualidad del hábito, puede ser intelectual y percibir intelectivamente su propio ser. Conserva, por tanto, algo de la inteligibilidad propia, de la autoconciencia, característica esencial del espíritu.

\section{LA AUTOCONCIENCIA PERFECTA}

En este pasaje de la Suma contra gentiles, continúa describiendo los distintos grados de perfección de la escala de los entes con la explicación del conocimiento angélico. Explica que: «La vida intelectual de los ángeles, cuyo entendimiento no parte de algo exterior para conocerse, porque se conoce en sí mismo, es más perfecta. A pesar de ello, su vida no alcanza la última perfección, porque aunque la idea entendida sea en ellos totalmente intrínseca, sin embargo, no es su propia substancia, puesto que en ellos no se identifica el entender y el ser».

En este segundo grado de vida intelectual, se da una mayor inmanencia. Hay una más plena interioridad, porque la emanaciọn de esta vida intelectual no procede ya del exterior. Desde el principio, el ángel goza de la plenitud de su sabiduría, debido a que en su propia naturaleza encuentra las especies inteligibles infundidas por Dios.

Su capacidad de entender, al igual que en el entendimiento humano, es adecuada por inteligibles, que son inmateriales, pero no por ser abstraídos por un entendimiento agente, sino porque son connaturales o inherentes a su misma substancia. Como explica Santo Tomás, en otro lugar: «En la 
mente de los ángeles están las semejanzas de las criaturas, pero no tomadas de ellas, sino de Dios, que es la causa de las criaturas y en quien primeramente existen las semejanzas de las cosas». ${ }^{69}$

A diferencia del conocimiento humano, el conocimiento angélico no es causado por las criaturas, sino por Dios, que les infundió la crearlos las especies inteligibles, que son una semejanza de sus ideas ejemplares, según las cuales creó todos los entes. «Los ángeles por dichas especies tienen un conocimiento perfecto de las cosas naturales, porque (...), Dios creó en la inteligencia angélica todo lo que creó en las propias naturalezas reales» ${ }^{70}$

No obstante, su entender no lo tiene en un grado en que se alcance la perfección total, ya que lo entendido, a pesar de su inmanencia perfecta, no es su misma substancia. En él, no se identifica el entender con su ser, no hay una inmanencia absoluta, una autoconiencia perfecta.

Finalmente concluye: «Luego, la última perfección de vida corresponde a Dios, en quien no se distinguen el entender y el ser, y así es preciso que en Dios se identifique la intención entendida con su divina esencia». Con esta identificación, se llega al último y perfecto grado de vida espiritual, al espíritu perfecto, en la que hay una interioridad perfecta.

Explica esta autoconciencia, precisando a continuación: «Digo intención entendida a lo que el entendimiento concibe en sí mismo acerca de la cosa entendida. Intención que, en nosotros, ni se identifica con la cosa que entendemos, ni con la substancia de nuestro entendimiento, sino que es una cierta semejanza de lo entendido concebida en el entendimiento y que la voz exterior significa; por eso, la intención entendida se llama verbo interior, que es significado por el verbo exterior».

Justifica la primera distinción entre el concepto y el objeto, advirtiendo que: «Se ve ciertamente que dicha intención no se identifica en nosotros con la cosa entendida, porque no es lo mismo entender la cosa que entender su intención, lo que hace el entendimiento cuando vuelve sobre su operación, de ahí que unas ciencias traten de las cosas y otras de las ideas entendidas».

La justificación de la segunda distinción, entre el concepto y el sujeto, la hace del siguiente modo: «Y que la intención entendida tampoco se identifica con nuestro entendimiento, lo vemos porque el ser de ella consiste en el mismo entenderse, en cambio, el ser de nuestro entendimiento es distinto de su propio entender».

Ninguna de estas distinciones se da en Dios. «Como en Dios se identifican el ser y el entender, la intención entendida y el entendimiento son en El una misma cosa. Y como el entendimiento y la cosa entendida se identifican también en $\mathrm{El}$, porque entendiéndose a sí, entiende todo los demás, resulta, pues, que en Dios, al entenderse a sí mismo, el entendimiento, la cosa que se entiende y la intención entendida son lo mismo».

Dios es, por tanto, la autoconciencia perfecta, que no excluye la locución intelectiva. «Dios se entiende a sí mismo. Más lo entendido, en cuanto tal, debe estar en quien lo entiende, porque entender es aprehender una cosa con el entendimiento. Por eso, incluso nuestro entendimiento al entenderse a sí mismo, existe no sólo como identificado con su esencia, sino también en el entendimiento aprehendido por él. Es necesario, pues, que Dios exista en sí mismo como lo entendido

69 Idem, Summa Theologine, I, q. 55, a. 2 ad 1.

70 Ibid., I, q. 89 , a. 2 , in c. 
en el inteligente. Pero lo entendido en el inteligente es la intención entendida y el verbo. Así pues, en Dios, que se entiende a sí mismo, existe el Verbo de Dios a modo de Dios entendido: como el verbo de la piedra existe en el entendimiento como piedra entendida. Por esto se dice en Juan I, 1: «El Verbo era Dios». 71

Eudaldo Forment

Baldiri i Reixac, s/n

08028-Barcelona

71 Idem, Summa Contra Gentes, IV, c. 11. 